\title{
Asparagus racemosus stem extract as corrosion inhibitor for mild steel in acid medium.
}

\author{
S.Ananth Kumar, A.Sankar*, S.Rameshkumar, M.Vijayan \\ ${ }^{a}$ Kandaswami Kandar's College, P. velur, Namakkal-638 182, India \\ ${ }^{b}$ PSG College of Technology Peelamedu, Coimbatore 641 004, India \\ ${ }^{c}$ Scientist , centre for conducting polymers, Eletrochemical materials science division, CECRI-630006,India
}

\begin{abstract}
The effect of addition of Asparagus racemosus stem extract on the corrosion of steel in $0.5 \mathrm{M}$ $\mathrm{H}_{2} \mathrm{SO}_{4}$ acid has been studied by weight loss measurements, potentiodynamic polarization and Electrochemical Impedance Spectroscopy (EIS) measurements. The inhibition efficiency was found to increase with inhibitors content to attain 51.11\% and 91.66\% Asparagus racemosus stem extract and 25ppm TBAB respectively. Data obtained from EIS studies were analyzed to determinate the model inhibition process through appropriate equivalent circuit models. Inhibition efficiency E (\%) obtained from the various methods is in good agreement.
\end{abstract}

Key words: - Inhibitor, Mass loss, Impedance, Polarization, Asparagus racemosus

\section{INTRODUCTION}

The issue of environmental pollution resulting from corrosion control measures involving the use of synthetic inhibitors in conjunction with acid solutions for the removal of rust and scale in industrial processes is also another source of anxiety. Acids are widely used in the industrial operations of pickling, descaling, oil well acidizing and cleaning of steel and ferrous alloys [2-9]. These operations ensure that machine components come in contact with these hostile species leading to metal loss or depletion in form of reduction in effective size of the component which may inevitably lead to catastrophic failure [9]. Several tested methods for preventing and controlling corrosion are influenced by the specific material to be protected; environmental concerns such as soil resistivity, humidity, and exposure to marine or industrial environments; the type of product to be processed or transported; and many other factors. The most commonly used methods include organic and metallic protective coatings; corrosion resistant alloys, plastics, and polymers; corrosion inhibitors; and cathodic protection technique which is used on pipings, underground storage cisterns, and offshore facilities that creates an electrochemical cell in which the surface to be protected is the cathode and corrosion reactions are abated [1]. It is well known that in developed countries corrosion mitigation management has improved over the past several decades, but more and better ways to encourage, support, and implement optimal corrosion control practices should be sought out. In a bid to inspire and sustain these efforts, practical attempts have been made by several researchers to investigate the effect of using green inhibitors to combat corrosion of metals in acid media [10-21]. These investigations have shown that green inhibitors represent a veritable source of environmentally friendly, cheaply available and easily applicable resource[5, 7]. In the present study, the corrosion inhibition properties for Asparagus racemosus stem extract have been investigated. To the best of our knowledge, nothing has been published on the use of the Asparagus racemosus stem extract for the inhibition of mild steel corrosion in acidic medium by various methods weight loss measurements, the polarization method and electrochemical impedance spectroscopy (EIS).

\section{MATERIALS AND METHODS}

\subsection{Preparation of Asparagus racemosus extract:}

An aqueous extract of Asparagus racemosus stem extract was prepared by grinding $5 \mathrm{~g}$ of plant leaves, with distilled water, filtering the suspending impurities, and making up to $100 \mathrm{ml}$. The extract was used as corrosion inhibitor in the present study.

\subsection{Preparation of specimens}

Carbon steel specimens $(0.022 \% \mathrm{~S}, 0.038 \% \mathrm{Mn}, 0.027 \% \mathrm{P}, 0.086 \mathrm{C})$ of dimension $1.0 \mathrm{~cm} * 4.0 \mathrm{~cm} * 0.2 \mathrm{~cm}$ were polished to a mirror finished with the emery sheets of various grades and degreased with trichloroethylene.

\subsection{Weight loss method.}

Carbon steel specimens in triplicate were immersed in $100 \mathrm{~mL}$ of the inhibited and uninhibited $0.5 \mathrm{M}$ $\mathrm{H}_{2} \mathrm{SO}_{4}$ solutions in the presence and absence of TBAB for two hours. The weight of each specimen before and 
after immersion was determined using shimadzu balance, model Ay 62.The inhibition efficiency (IE) was then calculated using the expression;

$$
\mathrm{IE} \%=\left(\frac{\mathrm{W}_{1}-\mathrm{W}_{2}}{\mathrm{~W}_{1}}\right) \times 100
$$

Where $\mathrm{W}_{1}$ and $\mathrm{W}_{2}$ are the corrosion rates in the absence and presence of the inhibitor, respectively.

\subsection{Electrochemical impedance measurements}

The impedance measurements were performed using a computer controlled potentiostat (model Solartron SI-1260) and the data were analysed using gain phase analyser electrochemical interface (Solartron SI-1287). A three electrode set up was employed with Pt foil as the auxiliary electrode and a saturated calomel electrode as the reference electrode. The Teflon coated mild steel rod, with the surface prepared as described in the weight loss experimental method, served as the working electrode. The measurements were carried out in the frequency range $10^{6}-10^{-2} \mathrm{~Hz}$ at the open circuit potential by superimposing sinusoidal AC signal of small amplitude, $10 \mathrm{mV}$, after an immersion period of $30 \mathrm{~min}$ in the corrosive media. The double layer capacitance $\left(\mathrm{C}_{\mathrm{dl}}\right)$ and charge transfer resistance $\left(\mathrm{R}_{\mathrm{ct}}\right)$ were obtained from the impedance plots as described elsewhere [22]. Because $R_{c t}$ is inversely proportional to corrosion current density, it was used to determine the inhibition efficiency (IE\%) using the relationship;

$$
\mathrm{IE} \%=\frac{\mathrm{Rct}-\mathbf{R}^{\circ} \mathrm{ct}}{\mathrm{Rct}} \times \mathbf{1 0 0}
$$

Where $\mathrm{R}_{\mathrm{ct}}$ and $\mathrm{R}_{\mathrm{ct}}^{0}$ are the charge transfer resistance values in the inhibited and uninhibited solutions respectively.

\subsection{Polarization measurements}

The potentiodynamic polarization curves were recorded using the same cell setup employed for the impedance measurements. The potentials were swept at the rate of $1.66 \mathrm{mV} / \mathrm{s}$, primarily from a more negative potential than $\mathrm{E}_{\mathrm{ocp}}$ to a more positive potential than $\mathrm{E}_{\text {ocp }}$ through $\mathrm{E}_{\mathrm{corr}}$. The inhibition efficiencies were calculated using the relationship [23];

$$
\mathrm{IE} \%=\frac{\mathrm{I}^{\circ} \text { corr }-\mathrm{Icorr}}{\mathrm{I}^{\circ} \text { corr }} \times 100
$$

Where $\mathrm{I}_{\text {corr }}^{0}$ and $\mathrm{I}_{\text {corr }}$ are the corrosion current densities in the absence and in the presence of inhibitor, respectively

\subsection{Analysis of results of mass loss method \\ RESULTS AND DISCUSSION}

The corrosion rates and inhibition efficiency values, calculated using weight loss data, for various concentrations of Sandal wood leaves extract in the presence and absence of TBAB the corrosion of carbon steel in $0.5 \mathrm{M} \mathrm{H}_{2} \mathrm{SO}_{4}$ solution are presented in Table.1. It is apparent that the inhibition efficiency increased with the increase in inhibitor concentration in the presence and absence of TBAB. This behavior can be explained based on the strong interaction of the inhibitor molecule with the metal surface resulting in adsorption. The extent of adsorption increases with the increase in concentration of the inhibitor leading to increased inhibition efficiency. The maximum inhibition efficiency was observed at an inhibitor concentration of $5 \mathrm{~mL}$. Generally, inhibitor molecules suppress the metal dissolution by forming a protective film adsorbed to the metal surface and separating it from the corrosion medium. The corrosion suppressing ability of the inhibitor molecule originates from the tendency to form either strong or weak chemical bonds with Fe atoms using the lone pair of electrons present on the $\mathrm{O}$ and $\pi$ electrons in benzene ring. It is also seen from table. 1 that the leaf extracts of Asparagus racemosus at $1 \mathrm{~mL}$ and $5 \mathrm{~mL}$ concentrations $51.11 \%$ and $72.02 \%$ inhibition efficiencies respectively, Then the values increased to $88.00 \%$ after adding $25 \mathrm{ppm}$ of TBAB solution in $0.5 \mathrm{M} \mathrm{H}_{2} \mathrm{SO}_{4}$ solutions containing $5 \mathrm{~mL}$ of Asparagus racemosus stem extract respectively. This showed a good synergistic effect between Asparagus racemosus stem extract and TBAB. 
Table1.Corrosion rate (CR) of mild steel in $0.5 \mathrm{M} \mathrm{H}_{2} \mathrm{SO}_{4}$ solutions the absence and presence of inhibitor and the inhibition efficiency (IE) obtained by mass loss method.

\begin{tabular}{|c|c|c|}
\hline \multirow{2}{*}{$\begin{array}{c}\text { Inhibitor concentration } \\
(\mathbf{m L})\end{array}$} & \multicolumn{2}{|c|}{ TBAB (0) $\mathbf{~ p p m}$} \\
\cline { 2 - 3 } & $\mathbf{C R}\left(\mathbf{m g ~ c m}^{-\mathbf{2}} \mathbf{h}^{-\mathbf{1}}\right)$ & IE \% \\
\hline 0 & 196.00 & - \\
\hline 1 & 105.26 & 46.30 \\
\hline 2 & 92.23 & 52.94 \\
\hline 3 & 70.12 & 64.22 \\
\hline 4 & 66.98 & 65.82 \\
\hline 5 & 64.52 & 67.08 \\
\hline
\end{tabular}

3.2 Influence of TBAB on the inhibition efficiency Asparagus racemosus stem

\begin{tabular}{|c|c|c|}
\hline Inhibitor concentration & \multicolumn{2}{|c|}{ TBAB (25) ppm } \\
\cline { 2 - 3 }$(\mathbf{m L})$ & $\mathbf{C R}\left(\mathbf{m g ~ c m}^{-2} \mathbf{h}^{-1}\right)$ & IE \% \\
\hline $\mathbf{5}$ & 29.16 & 85.12 \\
\hline
\end{tabular}

\subsection{Electrochemical impedance spectroscopic measurements (EIS)}

Impedance spectra obtained for corrosion of mild steel in $0.5 \mathrm{M} \mathrm{H}_{2} \mathrm{SO}_{4}$ contains a semicircle, representing the interaction of metal surface with the corrosive environment.. The $-\mathrm{R}(\mathrm{CR})$ model best describes this situation. The semicircle in the impedance plots contain depressed semicircles with the centre below the real axis. The size of the semicircle increases with the inhibitor concentration, indicating the charge transfer process as the main controlling factor of the corrosion of mild steel. It is apparent from the plots that the impedance of the inhibited solution has increased with the increase in the concentration of the inhibitor. The experimental results of EIS measurements for the corrosion of mild steel in $0.5 \mathrm{M} \mathrm{H}_{2} \mathrm{SO}_{4}$ in the absence and presence of inhibitor are given in Table 3. Said that sum of charge transfer resistance $\left(R_{c t}\right)$ and adsorption resistance $(\mathrm{Rad})$ is equivalent to polarization resistance $(\mathrm{Rp})$.

Table 3. Impedance parameters obtained from electrochemical impedance studies.

\begin{tabular}{|c|c|c|c|}
\hline $\begin{array}{c}\text { Inhibitor concentration } \\
(\mathrm{mL})\end{array}$ & $\begin{array}{c}\text { Rct } \\
\mathrm{Ohm} \mathrm{cm}^{2}\end{array}$ & $\begin{array}{c}\mathrm{C}_{\mathrm{dl}} \\
\mu \mathrm{F}\end{array}$ & IE\% \\
\hline 0 & 17.2 & $9.2578 \times 10^{-3}$ & - \\
\hline 5 & 53 & $3.004 \times 10^{-6}$ & 67.55 \\
\hline $5+25 \mathrm{ppm}(\mathrm{TBAB})$ & 124 & $1.284 \times 10^{-6}$ & 86.13 \\
\hline
\end{tabular}

Fig.1 Table 3. Impedance spectra obtained from electrochemical impedance studies

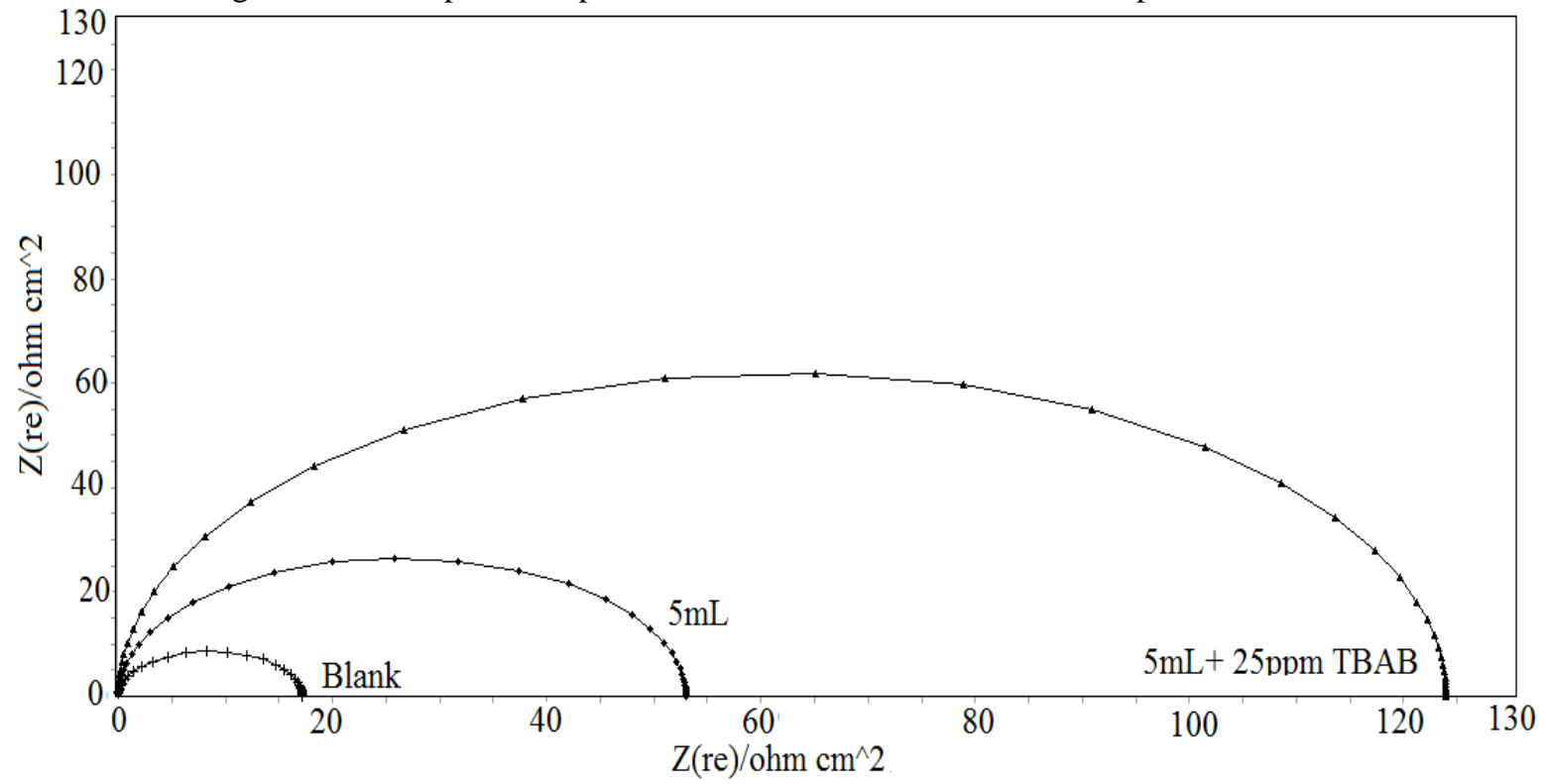




\subsection{Potentiodynamic Polarization studies:}

The polarization curves obtained for the corrosion of mild steel in the inhibited $(8 \mathrm{~mL})$ and uninhibited $0.5 \mathrm{M} \mathrm{H}_{2} \mathrm{SO}_{4}$ solutions in the absence and presence of TBAB are shown in Fig.2. Electrochemical parameters such as corrosion potential $\left(\mathrm{E}_{\text {corr }}\right)$, corrosion current density $\left(\mathrm{I}_{\text {corr }}\right)$, cathodic and anodic tafel slopes $\left(\beta_{\mathrm{c}}\right.$ and $\left.\beta_{\mathrm{a}}\right)$ and percentage inhibition efficiency according to polarization studies are listed in table 4 . Here $\mathrm{I}_{\text {corr }}$ decreased with increasing inhibitor concentration. From the figures, it can be interpreted that the addition of this inhibitor to corrosive media changes the anodic and cathodic tafel slopes. The changes in slopes showed the influence of the inhibitor both in the cathodic and anodic reactions. However, the influence is more pronounced in the cathodic polarization plots compared to that in the anodic polarization plots. Even though $\beta_{c}$ and $\beta_{a}$ values (table.3) change with an increase in inhibitor concentrations, a high $\beta_{c}$ value indicates that the cathodic reaction is retarded to a higher extent than the anodic reaction.

From Fig. 2 it is also clear that the addition of the inhibitor shifts the cathodic curves to a greater extent toward the lower current density when compared to the anodic curves. The $\mathrm{E}_{\text {corr }}$ value is also shifted to the more negative side with an increase in the inhibitor concentration. These shifts can be attributed to the decrease in the rate of the hydrogen evolution reaction on the mild steel surface caused by the adsorption of the inhibitor molecule to the metal surface [24]. It has been reported that a compound can be classified as an anodic and cathodic type inhibitor on the basis of shift of $\mathrm{E}_{\text {corr }}$ value. If displacement of $\mathrm{E}_{\text {corr }}$ value is greater than $85 \mathrm{mv}$, towards anode or cathode with reference to the blank, then an inhibitor is categorized as either anodic or cathodic type inhibitor otherwise inhibitor is treated as mixed type [25,26]. In our study, maximum displacement in $\mathrm{E}_{\text {corr }}$ value was around $9 \mathrm{mV}$, indicating the inhibitor is a mixed type and more anodic nature and does not alter the reaction mechanism. The inhibition effect has occurred due to simple blocking of the active sites, thereby reducing available surface area of the corroding metal[22,28,29,30]. The increase in inhibitor efficiency of inhibited $(8 \mathrm{~mL}) 0.5 \mathrm{M} \mathrm{H}_{2} \mathrm{SO}_{4}$ solution for the corrosion of mild steel after adding $25 \mathrm{ppm}$ TBAB shows synergism between inhibitor molecules and TBAB.

Table. 4. Corrosion parameters in the presence and absence of inhibitor obtained from polarization

\begin{tabular}{|c|c|c|c|c|c|}
\hline $\begin{array}{c}\text { Inhibitor concentration } \\
\mathrm{mL}\end{array}$ & $\begin{array}{c}-\mathrm{E}_{\text {corr }} \\
(\mathrm{mV})\end{array}$ & $\begin{array}{c}\beta_{\mathrm{c}} \\
(\mathrm{mV} /)\end{array}$ & $\begin{array}{c}\beta_{\mathrm{a}} \\
(\mathrm{mV})\end{array}$ & $\begin{array}{c}\mathrm{I}_{\text {corr }} \times 10^{*} 6 \\
\mu \mathrm{A}\end{array}$ & IE\% \\
\hline 0 & 491 & 180 & 80 & 1.628 & - \\
\hline 5 & 482 & 182 & 67 & 0.534 & 67.2 \\
\hline $5+\mathrm{ppm}(\mathrm{TBAB})$ & 483 & 183 & 61 & 0.221 & 86.41 \\
\hline
\end{tabular}

Fig 2. Potentiodynamic polarization curves of mild steel immersed in $0.5 \mathrm{M} \mathrm{H}_{2} \mathrm{SO}_{4}$ solution in the absence and presence of inhibitors

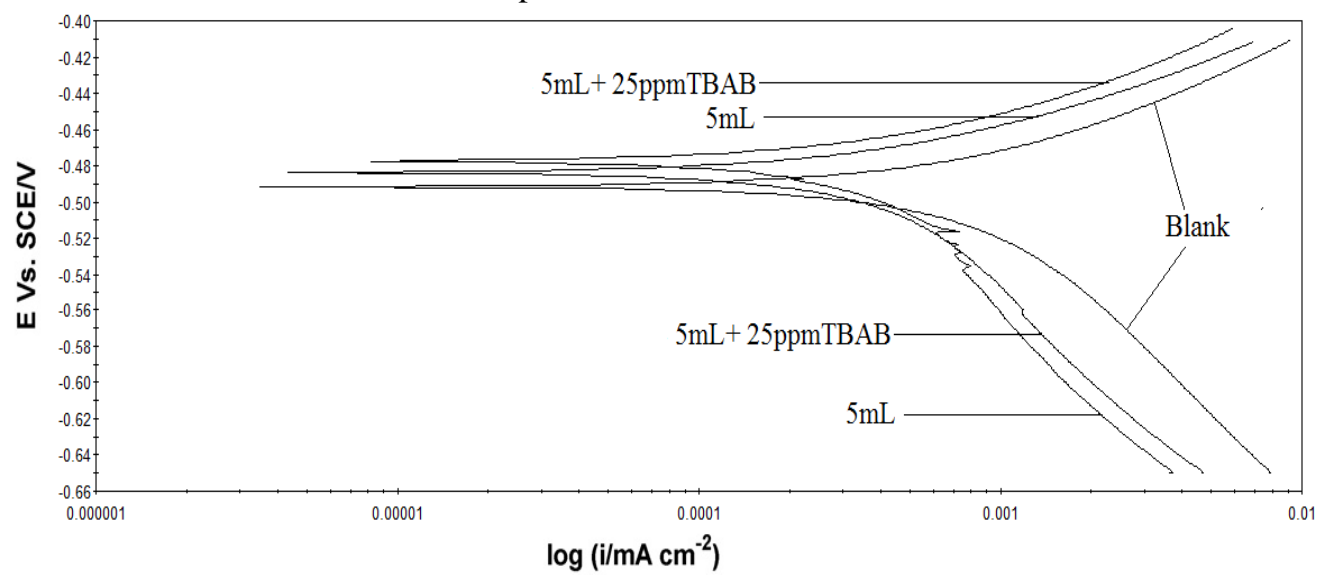

\subsection{Conclusion:}

The effect of acid concentration and the effect of addition the aqueous extract of Eragrostis cynosuroides on the corrosion of Mild steel has been studied. The following conclusions may be drawn:

1) The chemical results showed that the corrosion rate of mild steel sample is increase with increasing acid concentrations $2 \mathrm{~mL}$ to $8 \mathrm{~mL}$.

2) The polarization measurements also showed that, the increase of $0.5 \mathrm{M} \mathrm{H}_{2} \mathrm{SO}_{4}$ concentration leads to displacement of the anodic and cathodic curves to high current densities $\left(\mathrm{I}_{\text {corr. }}\right)$, also increase the corrosion rate will be found. 
3) The electrochemical impedance measurements showed that the corrosion of mild steel sample is mainly controlled by charge transfer process.

4) The aqueous extract of Eragrostis cynosuroides acts as good inhibitor for the corrosion of mild steel in 0.5 $\mathrm{M} \mathrm{H}_{2} \mathrm{SO}_{4}$ solution.

5) Electrochemical polarization results indicates that the Eragrostis cynosuroides act as mixed type inhibitor and impedance results showed that the corrosion of mild steel is mainly controlled by a charge transfer process and the presence of Eragrostis cynosuroides leaves extract in acid solution does not alter the mechanism of mild dissolution.

\section{AKNOWELEDGEMENTS}

The authors generously acknowledge the support by Dr.R.Somasundaram M.D., Dr.R.Arul M.Sc.,Ph.D., Dr.S.Vedanayaki M.Sc.,Ph.D.,President ,Principal and head of the department chemistry respectively of Kandaswami Kandar's College,P.Velur for providing necessary chemical and lab facilities to carry out chemical studies..

\section{REFERENCES}

[1] Koch, G. H., Brongers, M. P. H., Thompson, N. G., Virmani, P., Payer, J.H. F.HWA-RD-01-156 (2001) [available at http://www.corrosioncost.com/pdf/main.pdf] accessed 20/03/2011.

[2] Faltermeier, R., AMT: A new corrosion inhibitor. B.Sc report, University College London, London (1992).

[3] Iannuzzi, M., Young, T., Frankel, G.S. Journal of the electrochemical society, 153 (2006) 533.

[4] Ralston, K.D. Chromate free corrosion inhibitors of aluminium alloys: Vanadates and anionic exchange

[5] clay pigments. Ph. D dissertation, Ohio State University, Ohio. (2008). Ahamad, I., Quraishi, M.A. Corros. Sci. 51 (2009) 2006.

[6] Ralston, K.D., Young, T.L. Buchheit, R.G. Journal of the electrochemical society, 156 (2009) 135. Khaled K.F, El-mghraby, A., Ibrahim, O.B., Elhabib, O.A., Ibrahim, M.A.M. J. Mater. Environ. Sci. 1 (2010) 139.

[7] Omotosho, O.A., Okeniyi, J.O. Ajayi, O.O. J Fail. Anal. And Preven., 10 (2010) 408.

[8] Ajayi, O.O., Omotosho, O.A., Ajanaku, K.O., Olawore, B.O. J. Eng. Applied Sci., 6 (2011) 10.

[9] Oguzie, E.E. Corros. Sci. 50 (2008) 2993.

[10] Okafor, P.C., Ikpi, M.E., Uwaha, I.E., Ebenso, E.E., Ekpe, U.J., Umoren, S.A. Corros. Sci. 50 (2008)2310.

[11] Valek, L., Martinez, S. Mater. Lett. 61 (2007) 148.

[12] Singh, Ambrish, Ahamad, I., Singh, Vinod Kumar, Quraishi, M.A. (2010) J.S.E.L. 2010 JSEL-D-1000143R2.

[13] Raja, P.B., Sethuraman, M.G. Mater. Lett. 62 (2008) 1602.

[14] Singh, A., Singh, V. K., Quraishi, M. A. J. Mater. Environ. Sci. 1 (2010) 162.

[15] Noor, E.A. J. Engg. Appl. Sci. 3 (2008) 23.

[16] Buchweishaija, J., Mhinzi, G.S. Port. Electrochim. Acta 26 (2008) 257.

[17] El-Etre, A.Y. Corros. Sci. 45 (2003) 2485.

[18] Badiea, A.M., Mohana, K.N. J. Mater. Eng. Perform. 18 (2009) 1264.

[19] Noor, E.A. J. Appl. Electrochem. 39 (2009) 1465.

[20] De Souza, F.S., Spinelli, A. Corros. Sci., 51 (2009) 642

[21] Ashassi-Sorkhabi.H,.Shaabani.B,Seifzadeh.D, (2005 ) Electrochim. Acta, ,50 ,3446.

[22] Shahin.M, Bilgie.S, Yilmaz.H, (2003)Appl. Surf. Sci.,195: 1

[23] Silverman D. C., "Practical Corrosion Prediction Using Electrochemical Techniques", ch. 68 in Uhlig's Corrosion Handbook, $2^{\text {nd }}$ edition (Revie,.R.W, ed.), (2000)The Electrochemical Society,

[24] Prabhu., T.V. Venkatesha, A.V. Shanbhag. Praveen. B.M, Kulkarni. G.M,.Kalkhambkar R.G, (2008),Mater. Chem. Phys. $108: 283$

[25] Sanghvi. R.A, M.J., et al., (1999 0 Bull. Electrochem. 13: 358.

[26] Felicia Rajammal Selvarani, S.Santhanalakshmi, J. Wilson sahayaraja, A. John Amalraj,and Susai Rajendran , (2004) Bull. Electrochemistry. 20 : 561-565.

[27] Susai RajendranS. Mary Reenkala, Noreen Anthony and Ramaraj,R., (2002) Corros Sci, 44: 2243-2252.

[28] Kumaravel Mallaiyaa, Rameshkumar Subramaniama, Subramanian Sathyamangalam Srikandana,S. Gowria, N. Rajasekaranb, A. Selvaraj, (2011)Electrochimica Acta 56 ; 3857-3863

[29] S. Ananth Kumar., A.Sankar, and S. Ramesh Kumar, (2013). International Journal of Chemistry and Chemical Engineering. Volume 3, Number 1; pp. 7-14 